\title{
First report of brown rot caused by Monilinia fructicola (Winter) Honey on sweet cherry in Turkey
}

\author{
Ayşe Uysal $^{1}$ [D $\cdot$ Pervin Kinay-Teksür $^{2} \cdot$ Dilek Poyraz $^{1}$
}

Received: 25 April 2018 / Accepted: 14 January 2019/Published online: 5 March 2019

(C) Società Italiana di Patologia Vegetale (S.I.Pa.V.) 2019

Keywords Monilinia fructicola $\cdot$ Brown rot $\cdot$ Sweet cherry $\cdot$ PCR

Monilinia fructicola (Winter) Honey is an important causal agent of brown rot of stone fruits, which is present in Asia, Oceania, North and South America but listed as a quarantine organism in Europe. Orchard surveys on sweet cherry (Prunus avium) were carried out in Kemalpasa, Izmir in 2015 and 2016. Four isolates were obtained from blossoms and fruits of cherry in only one orchard in Kemalpasa. Pathogenicity was tested by inoculating healthy surface-sterilized apples with agar plugs bearing mycelia from a seven-day-old culture. Control fruits were inoculated with sterile agar plugs. After seven days of incubation at $22 \pm 2{ }^{\circ} \mathrm{C}$ and $95 \%$ relative humidity, typical brown rot symptoms developed around the inoculation point, while controls showed no symptoms. M. fructicola was reisolated from lesion margins. The isolates were identified as Monilinia fructicola based on morphological and molecular characters and sequence analysis. The colonies were yellowish gray and dense, with hazel sporogenous mycelium. Sporulation was abundant and usually developed in concentric rings. The lemon-shaped spores had an average size of 7.5-12.5 $\times 15-22.5 \mu \mathrm{m}$, which is consistent with M. fructicola. Morphological characterization was confirmed by PCR with ITS specific primers ITS1Mfcl-F and ITS4MfclR (Ioos and Frey 2000). Sequences of the PCR product for all four isolates were deposited in GenBank with the accession numbers MH020211, MH020212, MH020213 and MH020214. BLASTn analyses of the PCR products revealed between 99 and $100 \%$ identity with reference sequence KX982695, from CBS 329.35 (Honey 1928) in NCBI GenBank. ITS sequencing and morphological characteristics showed that the fungus is Monilinia fructicola. To our knowledge, this is the first report of presence of M. fructicola causing brown rot disease on cherry in the Aegean region, Turkey. In the cherry orchards where the pathogen was found, the necessary quarantine measures were quickly taken to prevent the spread of the disease.

Publisher's note Springer Nature remains neutral with regard to jurisdictional claims in published maps and institutional affiliations.

\section{References}

Honey EE (1928) The monilioid species of Sclerotinia. Mycologia 20: $127-157$

Ioos R, Frey P (2000) Genomic variation within Monilinia laxa, $M$. fructigena and M. fructicola, and application to species identification by PCR. Eur J Plant Pathol 106:373-378
Ayșe Uysal

ayse.uysal@tarim.gov.tr

1 Directorate of Plant Protection Research Institute-Bornova, İzmir, Turkey

2 Department of Plant Protection, Faculty of Agriculture, Ege University, İzmir, Turkey 